\title{
Hypertension in a Dental School Patient Population
}

\begin{abstract}
Sara D. Kellogg, B.A.; John P. Gobetti, D.D.S., M.S.
Abstract: Patient records were retrospectively reviewed to investigate the incidence of hypertensive patients seen at a U.S. dental school. This research was conducted to create an awareness of the current problems in diagnosing and treating hypertensive patients in the dental environment. Nine hundred and seventy-six records of patients seen between January 1, 1999 and January 1, 2000 were reviewed. Five hundred records that met specific study criteria related to health history, medications used, recorded blood pressure, and other criteria were selected for the study. Factors examined included demographic data consisting of age, sex, and ethnicity; history of hypertension; Joint National Committee on Detection, Evaluation, and Treatment of High Blood Pressure classification; control of hypertension; and medications used. The data demonstrated that 32 percent of the patients were hypertensive, 49 percent of whom were unaware of their high blood pressure prior to their dental visit. Nearly 9 percent of the hypertensive patients with elevated blood pressure had to be immediately sent for medical consult before they could receive dental treatment. The average blood pressure of the hypertensive patients was systolic 145.6 and diastolic 87.9 with a range of 110 to 240 systolic, 60 to 135 diastolic. Of the diagnosed patients, 41.9 percent were taking antihypertensive medication for their condition, and 13 percent were taking two or more medications. Nearly one third of a sample of 500 dental school clinic patients had high blood pressure in this retrospective study. This study demonstrates that it is crucial that dental providers take blood pressure readings for screening, monitoring of hypertensive patients, and appropriate dental care.
\end{abstract}

Ms. Kellogg is a dental student and Dr. Gobetti is Professor and Director, Undergraduate Oral Medicine and Diagnosis, Department of Oral Medicine, Pathology, and Oncology — both at the University of Michigan School of Dentistry, Department of Oral Medicine, Oncology, and Pathology. Direct correspondence and requests for reprints to Ms. Sara Kellogg, University of Michigan School of Dentistry, 1011 N. University Avenue, Room \#G018, Ann Arbor, MI 48109-1070; 734-476-6705 phone; 734-764-2469 fax; skellog@umich.edu.

Key words: hypertension, diagnosis, patient care

Submitted for publication 11/12/03; accepted 6/24/04

A ccording to the Seventh Report of the Joint National Committee on Prevention, Detection, Evaluation, and Treatment of High Blood Pressure (JNC VII Report) that was released in May 2003, hypertension affects approximately 50 million people in the United States between the ages of twenty-five and seventy-four years, or approximately one out of every four people in this age range. ${ }^{1}$ Since the publication of the Sixth Report of the Joint National Committee on the Prevention, Detection Evaluation, and Treatment of High Blood Pressure (JNC VI), many large-scale clinical trials have been published. ${ }^{1}$ The vast amount of new, updated clinical studies demonstrated there is a need for clear and concise guidelines for clinicians and was the motivation for the report. Two major modifications to the JNC VI report have been included. Individuals whose blood pressures range from 120/80 to 139/89 are now placed into a pre-hypertensive category. Patients with pre-hypertension are at increased risk for progression to hypertension; those in the $130 / 80$ to $139 /$ $89 \mathrm{~mm} \mathrm{Hg}$ blood pressure range are at twice the risk of hypertension as those with lower values. ${ }^{1}$ Additionally, stages two and three were previously desig- nated as blood pressure ranges from (Stage II) systolic $160-179 \mathrm{~mm} \mathrm{Hg}$ /diastolic $100-109 \mathrm{~mm} \mathrm{Hg}$ and (Stage III) $\geq 180 / \geq 110$ as defined by the JNC VI report have now been combined. ${ }^{2}$ The report states that systolic blood pressure of more than $140 \mathrm{~mm}$ $\mathrm{Hg}$ is a much more important cardiovascular disease risk factor than diastolic blood pressure in persons fifty years and above. The JNC VII also made available antihypertensive medications and therapeutic guidelines that are more concise and useful for clinicians. The JNC VII is presented in two separate publications: a succinct, practical, user-friendly guide and a more comprehensive report that provides further justification for the newly implemented guidelines.

It should be noted that, during the summer of 2002 when this study was conducted, the JNC VI guidelines were still operative and stage I hypertension was defined as a systolic of above $140 \mathrm{~mm} \mathrm{Hg}$ and/or a diastolic blood pressure of above $90 \mathrm{~mm}$ $\mathrm{Hg}$. Thus, in this study we will refer to hypertension in terms of the older guidelines taken from the sixth report of the Joint National Committee on Detection, Evaluation, and Treatment of High Blood Pressure. 
Table 1 presents the JNC VI blood pressure classification used in this study.

Although hypertension is the most prevalent health problem among adult primary care patients in the United States, its recognition and treatment are suboptimal. ${ }^{3}$ The only way hypertension can be diagnosed is by measuring a person's blood pressure. ${ }^{4}$ Once detected, treatment methods have reduced the risk of cardiovascular disease and fatality by as much as 30 percent. ${ }^{5}$ Because measuring a person's blood pressure is the principal screening method for hypertension and most Americans do not routinely take their own blood pressure readings, hypertension often goes unnoticed. Therefore, many hypertensive sufferers are unaware of their disorder.

Based on the findings and recommendations of the Joint National Committee on Prevention, Detection, Evaluation, and Treatment of High Blood Pressure, it should be recommended that dentists and student dentists take blood pressure readings on all patients before providing dental care. In addition, routine blood pressure determination in the dental office offers an excellent public health service to screen for hypertension. Dentists have the unique opportunity to play a more active role in the detection of hypertension. Most patients visit their dentists when they perceive themselves as healthy, but see their physicians only when they are sick. This behavior gives dental clinicians an opportunity to screen for underlying medical conditions such as hypertension of which the patient may have been previously unaware. $^{6}$

For this project, we hypothesized that dentists and student dentists treat a significant number of hypertensive patients annually. Additionally, it was believed that a large number of these hypertensive patients were unaware of their condition. Using a patient pool taken from a U.S. dental school over a one year span, the number of hypertensive patients treated in a dental school was determined. We then analyzed characteristics of this discovered hypertensive population and compared it to national data and trends.

The American Dental Association (ADA) is a contributing member of the coordinating committee of the Joint National Committee on Prevention, Detection, Evaluation, and Treatment of High Blood Pressure and the National High Blood Pressure Education Program. The ADA supports dental professionals' establishing a patient's average blood pressure and screening for hypertension. ${ }^{2}$ However, designated blood pressure guidelines for the dental

\section{Table 1. Classification of blood pressure for adults aged eighteen years and older as defined by the Joint Committee on Detection, Evaluation, and Treatment of High Blood Pressure}

\begin{tabular}{cccc} 
Category & \multicolumn{3}{c}{ Blood Pressure, mm Hg } \\
& Systolic & & Diastolic \\
\hline Optimal & $<120$ & and & $<80$ \\
Normal & $<130$ & and & $<85$ \\
High-Normal & $130-139$ & or & $85-89$ \\
Hypertension & & & \\
Stage 1 & $140-159$ & or & $90-99$ \\
Stage 2 & $160-179$ & or & $100-109$ \\
Stage 3 & 180 & or & 110
\end{tabular}

Source: National High Blood Pressure Education Program. The sixth report of the Joint National Committee on Detection, Evaluation, and Treatment of High Blood Pressure. Arch Intern Med 1997;157:2413-46.

schools and private practices are still lacking. This research was conducted in anticipation of creating a national awareness of the prevalence of hypertension in the patient population, so that appropriate steps may be taken to improve current diagnosis, treatment, and management of hypertensive dental patients.

\section{Methods}

Data collected for this study were taken from the clinical records of patients seen at the University of Michigan's School of Dentistry Adult Comprehensive Care Clinics between January 1, 1999 and January 1, 2000. Approval from the University of Michigan's Health Sciences Institutional Review Board was obtained before any preliminary research was conducted. Approval was obtained from the board in early June of 2002 after the submission of a detailed, written explanation regarding the specific nature, goals, and potential benefits of the research project. Patient charts were accessed through the computerized dental school database called Axium.

Five hundred "useable" records were obtained by examining 976 randomly selected records meeting the following criteria: completed patient medical, dental, and clinical history forms, lists of medications used, and recorded systolic and diastolic blood pressures. Factors examined within these elements included a demographic profile, hypertension history, JNC blood pressure classification, treatment 
of hypertension, other medications used, and tobacco and alcohol use. The correlation among age, gender, ethnicity, and medical treatment was also examined as it relates to hypertension. The average age of the overall sample of 500 patients was 36.5 years. Fiftyseven percent of the total patient population was female; 43 percent were male. Of the total sample population examined, 352 patients' ethnicities were not documented in their charts. Of those documented, ninety-seven were Caucasian, twenty-six were African American, five were Hispanic, eight were Asian, two were Native American, and ten patient's ethnicities were documented as "other."

The collected data was sorted into hypertensive patients or non-hypertensive subgroups. Within both groups, blood pressure readings, age, sex, ethnicity, and tobacco and alcohol use were recorded and evaluated. However, more detailed record evaluation was conducted with the hypertensive group (see Table 2). Data collected within the hypertensive subgroup additionally included JNC classification, prior diagnosis of hypertension, number of years with hypertension, treatment of hypertension, number and frequency of anti-hypertensive medications taken by patient, other medical treatments patient is/was undergoing, other diseases, and other prescription medications being taken. Hypertension classification taken from the JNC VI national report ranged from JNC hypertension stages I (systolic 140 to 159 or diastolic 90 to 99), to JNC hypertension stage III, "hypertensive crisis" stage (systolic $\geq 180$, diastolic $\geq$ 110). JNC classifications were taken from the $A r-$ chives of Internal Medicine, 1997, volume 157 (see Table 1). ${ }^{2}$ It should be noted that when protocol was followed, the last recorded, same day blood pressure (second, third, or fourth readings) was the value used in this study in order to most accurately report JNC class and eliminate initial high blood pressures associated with dental anxiety.

Also within the hypertensive subgroup, the record keeping of the student dentists was documented as to 1) whether a student recorded when a patient had a history of hypertension, 2) how often blood pressures were taken during dental appointments, 3) how many patients had to be sent for medical consult before being treated at the dental school, and 4) how many patients who were previously unaware of their elevated blood pressures were notified by the student dentists.

\section{Results}

Through the examination of 500 selected patient records, it was determined that 32 percent of the dental school's patient population was hypertensive. One hundred-sixty patients of the total patient pool suffered from hypertension; 49 percent were unaware of their high blood pressure prior to their dental visit. Three hundred-forty patients, or 68 percent, were normotensive (see Figure 1). Of the 500 patients, 285 (57 percent) were female, and 215 (43 percent) were male. Seventy-four or 46.3 percent of the 160 hypertensive patients in this study were male, and eighty-six or 53.8 percent were female (see Figure 2). Fourteen, or 8.8 percent, of the hypertensive patients had blood pressures in a dangerous range and had to be immediately sent for medical consult.

Approximately 62 percent (ninety-nine) of hypertensive patients were classified as JNC stage I patients. Of these ninety-nine patients, sixty were not previously diagnosed and were unaware of their hypertension. Thirty patients, or 18.8 percent, were classified as JNC stage II patients. Of these hyperten-

Table 2. Example of spreadsheet used in the data collection of hypertensive patients of this study

\begin{tabular}{|c|c|c|c|c|c|c|c|c|c|c|}
\hline \multicolumn{10}{|c|}{ Spreadsheet used in the Data Collection of Hypertensive Patients in a Dental School Population } & \\
\hline & & & & & & & & & & \\
\hline & & & & & & & & & & \\
\hline & & & & & & & & & & \\
\hline & & & & & \# of Years & Ever use & Alcohol intake & Most Recent & How Has Oral & \\
\hline Patient \# & Reg.\# & $\underline{\text { Age }}$ & Ethnicity & $\underline{\text { Sex }}$ & as Patient & Tobacco & per month & Oral Hygiene Status & Hygiene Changed & Systemic \\
\hline & & & & & & & & & & \\
\hline & & & & & & & & & & \\
\hline & & & & & & & & & & \\
\hline & & & & & & & & & & \\
\hline & & & & & & & & & & \\
\hline
\end{tabular}




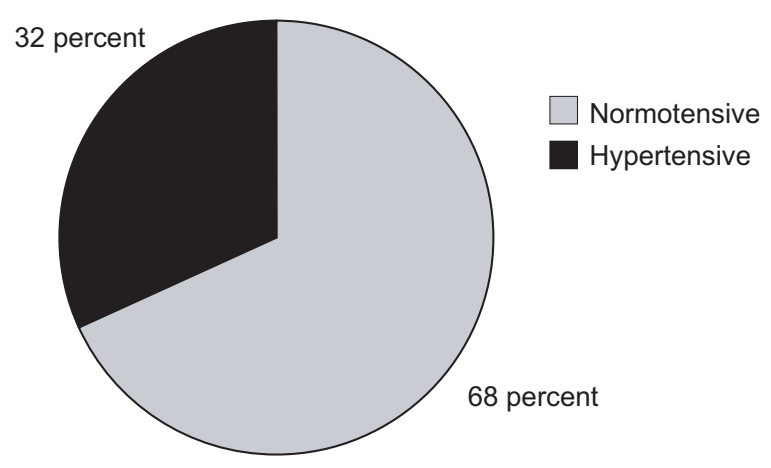

Figure 1. Normotensive vs. hypertensive patients in the dental school population

sive stage II patients, eighteen were not previously diagnosed with hypertension. Eight patients, or 5 percent, of the hypertensive patients seen were classified as JNC stage III. One of these patients was not previously diagnosed with hypertension (see Figure 3). Seven patients or 4.4 percent of the hypertensive population were previously diagnosed as suffering from hypertension, but exhibited blood pressure readings below JNC hypertension stage I levels. All but one of these patients were being treated with antihypertension medication. Sixteen patients (10 percent) whose medical history forms indicated they had hypertension apparently never had their blood pressures measured before, during, or after their dental appointment. As a result, it was not possible to determine their JNC classification.

Table 3 shows the breakdown of the dental school population in terms of age classification.

\begin{tabular}{|c|c|c|c|}
\hline & & & \\
\hline & & & \\
\hline \# Cleanings & & Amount of & Satisfied w/ Appearance \\
\hline per Year & \# Brushings & $\widehat{\text { Sugar in Diet }}$ & of Your teeth \\
\hline & & & \\
\hline & & & \\
\hline & & & \\
\hline & & & \\
\hline & & & \\
\hline
\end{tabular}

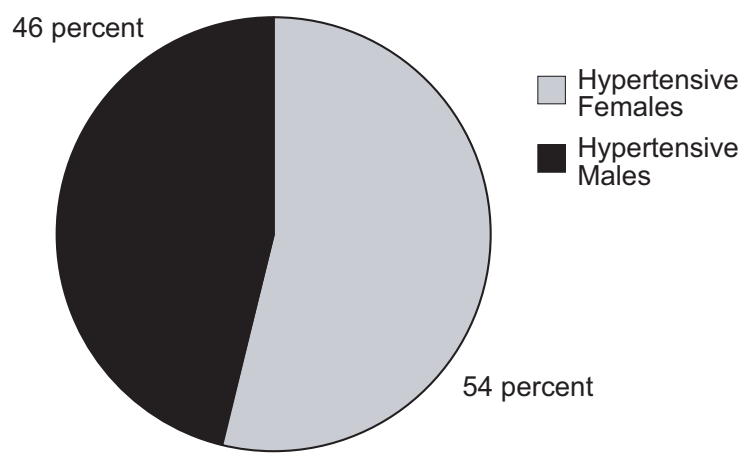

Figure 2. Hypertensive patient totals by gender

Forty-six of the patients, or 9 percent, were between the ages of fourteen and nineteen; of these, 13 percent (six people) were hypertensive. One hundredsixty-three patients, or 33 percent, were between the ages of twenty and twenty-nine; of these, 17.2 percent (twenty-eight) were hypertensive. One hundredeleven patients, or 22 percent, were between the ages of thirty and thirty-nine; of these, 32.4 percent (thirtysix) were hypertensive. Seventy-five patients of the total patient pool of 500 , or 15 percent, were between the ages of forty and forty-nine; of these, 25.3 percent (nineteen) were hypertensive. Fifty-three patients, or 11 percent, were between the ages of fifty and fifty-nine; of these, 64.2 percent (thirty-four) were hypertensive. Twenty patients, or 4 percent, were between the ages of sixty and sixty-nine; of these, 75 percent (fifteen) were hypertensive. Seventeen patients, or 3 percent, were between the ages of seventy and seventy-nine; of these, 58.8 percent (ten) were hypertensive. Ten patients of the total patient pool, or 2 percent, were between the ages of eighty and eighty-nine; all ten of these patients (100 percent) were afflicted with hypertension. Five patients, or 1 percent, were between the ages of ninety and ninety-nine; of these, 40 percent (two) were hypertensive.

Of the 160 hypertensive patients, sixty-five, or 41 percent, had been previously diagnosed and were receiving antihypertensive medication to treat their condition. Eighteen patients, 11 percent, had been diagnosed in the past but were not taking antihypertensive medication at the time of their dental appoint- 


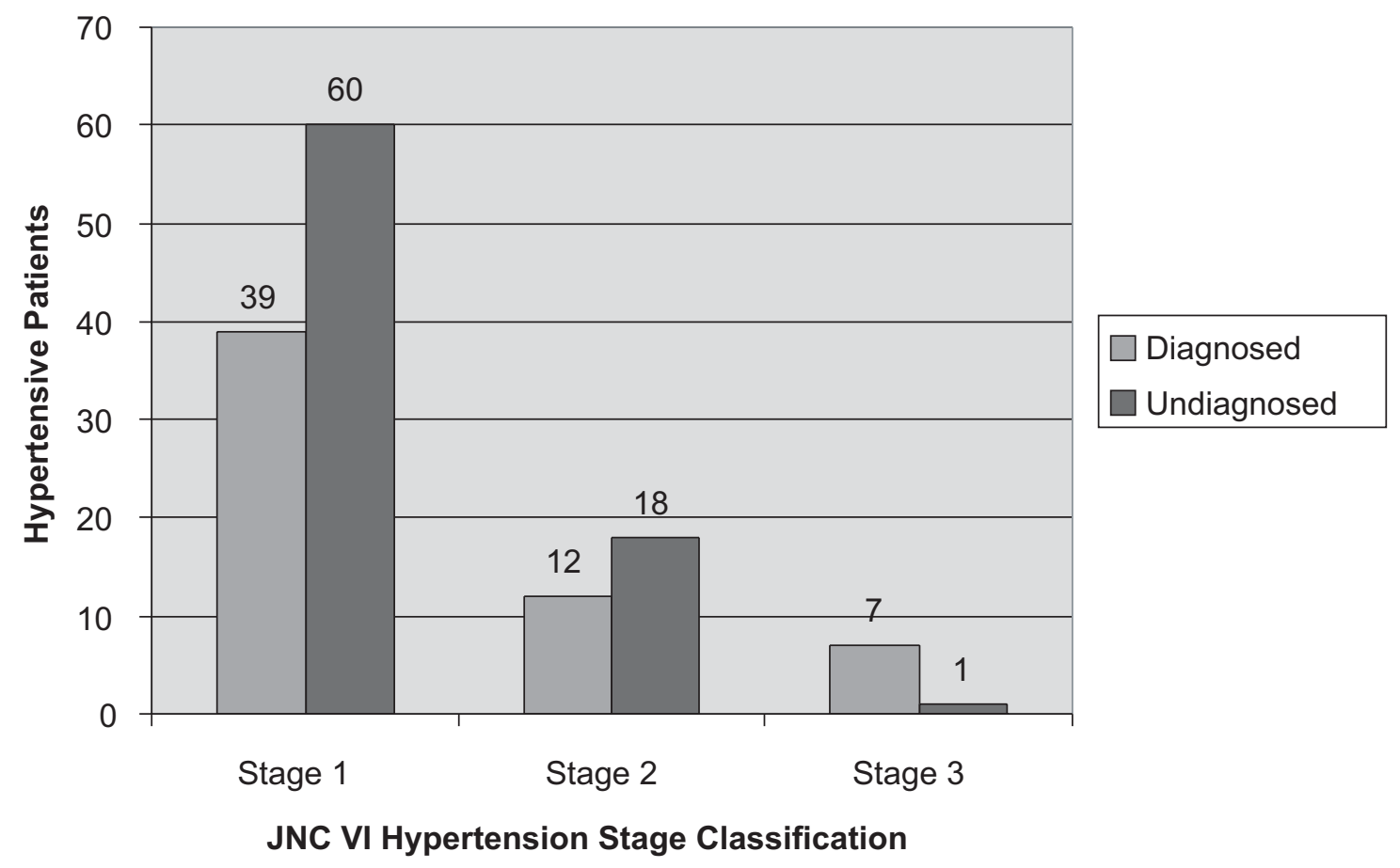

Figure 3. Breakdown of hypertensive patients based on JNC VI classification

ments. Seventy-seven patients, or 48 percent, had a clinical blood pressure above recommended JNC levels, had not been previously diagnosed by a physician, and were consequently not taking any antihypertensive medication or treatments (see Figure 4).

Table 3. Age breakdown of total patient population versus hypertensive patient and the prevalence of hypertension within each age group

\begin{tabular}{cccc}
$\begin{array}{c}\text { Age Group } \\
\text { (years) }\end{array}$ & $\begin{array}{c}\text { Total Patient } \\
\text { Population }\end{array}$ & $\begin{array}{c}\text { Hypertensive } \\
\text { Patient } \\
\text { Population }\end{array}$ & $\begin{array}{c}\text { Prevalence of } \\
\text { Hypertension } \\
\text { within } \\
\text { Age Group }\end{array}$ \\
\hline $14-19$ & 46 & 6 & $13.0 \%$ \\
$20-29$ & 163 & 28 & $17.2 \%$ \\
$30-39$ & 111 & 36 & $32.4 \%$ \\
$40-49$ & 75 & 19 & $25.3 \%$ \\
$50-59$ & 53 & 34 & $64.2 \%$ \\
$60-69$ & 20 & 15 & $75.0 \%$ \\
$70-79$ & 17 & 10 & $58.8 \%$ \\
$80-89$ & 10 & 10 & $100 \%$ \\
$90-99$ & 5 & 2 & $40 \%$ \\
\hline
\end{tabular}

Table 4 illustrates the frequencies of antihypertensive medications taken by hypertensive patients in the dental school's patient pool. It was found that twenty-six, or 39.4 percent of the hypertensive patients being treated for hypertension used ACEInhibitors, 30.3 percent (twenty patients) used a form of Beta-Blockers, 33.3 percent (twenty-two) used diuretics, 6.1 percent (four) used Alpha-Blockers, 27.3 percent (eighteen) used $\mathrm{Ca}^{+}$Channel Blockers, 4.5 percent (three) were taking an Angiotension II Antagonist, and two patients were taking the centrally acting drug, Clonidine. Thirteen percent of the patients being treated for hypertension were taking two or more antihypertension medications.

The use of tobacco and alcohol by hypertensives and normotensives was also evaluated. It was found that 58.1 percent of the patients diagnosed with hypertension were regular tobacco users and 36.9 percent were weekly alcohol users, whereas 56.6 percent of the normotensive patients were regular tobacco users and 54.9 percent were regular alcohol users. The differences for both tobacco use and alcohol were not statistically significant between the two groups. 

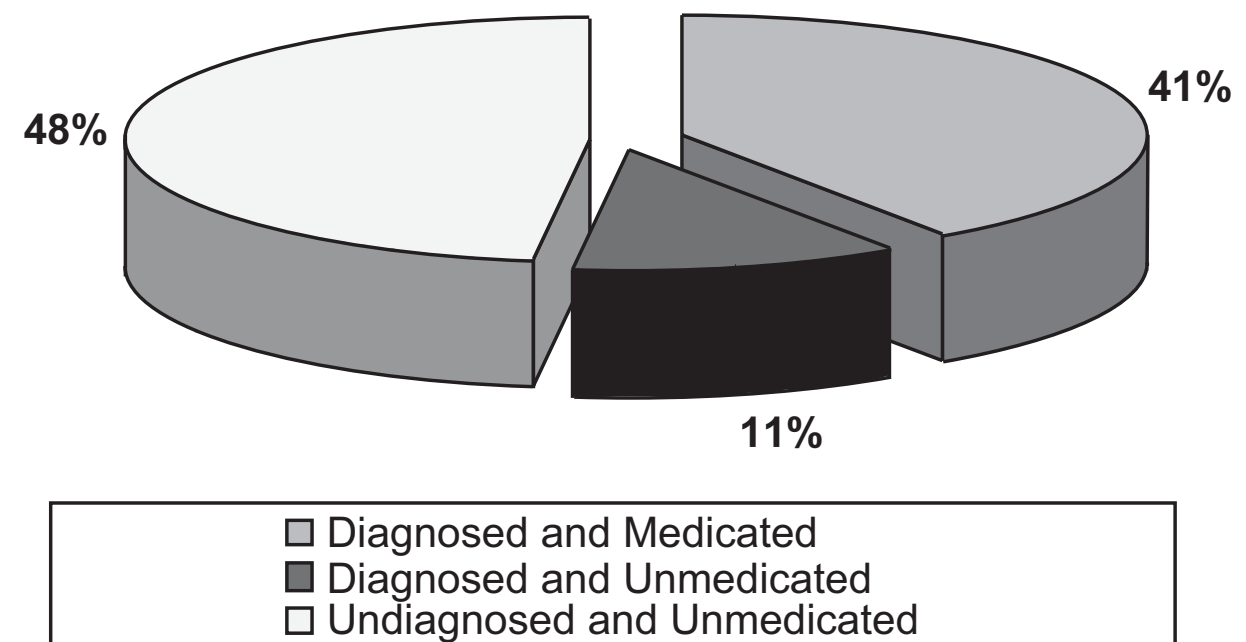

Figure 4. Hypertensive vs. normotensive diagnoses and medicinal treatment

It should be noted that had the JNC VII instead of the JNC VI report been used to analyze the results of this study, the population of hypertensive patients would have been even larger, because patients falling into the pre-hypertensive category (120-139/80$89)$ would also have had to be considered.

\section{Discussion}

The research was conducted because of the number of individuals who suffer from hypertension and the fact that the dental setting is viewed as a stressful environment for some individuals. The combination of high blood pressure and a stressful environment may have harmful, even fatal consequences for patients. Though not released until after this study, the newly released JNC VII report adjusts blood pressure classifications and recommendations for treatment, making it more imperative that health care providers be aware of patients' blood pressures.

It was found that 32 percent of the examined population treated at the University of Michigan School of Dentistry were hypertensive. This number is alarming, but even more so given that 49 percent of the examined hypertensive patient pool were

\section{Table 4. List and frequencies of antihypertensive medications used by patients}

\begin{tabular}{|c|c|c|c|c|c|c|}
\hline ACE-Inhibitors & $\begin{array}{l}\text { Angiotensin II } \\
\text { Antagonists }\end{array}$ & Beta-Blockers & $\begin{array}{c}\mathrm{Ca}^{2+} \text { Channel } \\
\text { Blockers }\end{array}$ & Diuretics & Alpha-Blockers & $\begin{array}{l}\text { Other Anti- } \\
\text { Hypertensives }\end{array}$ \\
\hline $26=39.4$ percent & $3=4.5$ percent & $20=30.3$ percent & $18=27.3$ percent & $22=33.3$ percent & $4=6.1$ percent & $2=3.0$ percent \\
\hline $\begin{array}{c}\text { Lisinopril } \\
\text { Enalapril } \\
\text { Fosinopril } \\
\text { Quinapril } \\
\text { Captopril } \\
\text { Benazepril } \\
\text { Ramipril } \\
* \text { contains diuretic }+ \\
* \text { contains diuretic }\end{array}$ & $\begin{array}{l}\text { Beta-Blocker } \\
\text { Alpha-Blocker }\end{array}$ & $\begin{array}{c}\text { Atenolol } \\
\text { Metoprolol XL } \\
\text { Nadolol } \\
\text { Propranolol } \\
* \text { Bisoprolol Fumarate } \\
* \text { Chlorthalidone/Atenolc } \\
* * \text { Labetalol } \\
* * \text { Carvedilol }\end{array}$ & $\begin{array}{l}\text { Amlodipine } \\
\text { Diltiazem XL } \\
\text { Nifedipine XL } \\
\text { Verapamil SR } \\
\text { lol }\end{array}$ & $\begin{array}{c}\text { Furosemide } \\
\text { Spironolactone } \\
\text { Hydrochlorothiazside } \\
\text { Bumetanide } \\
\text { Indapamide } \\
\text { Amiloride }\end{array}$ & $\begin{array}{l}\text { Prazosin } \\
\text { Terazosin } \\
\text { Doxazosin } \\
\text { Cardura }\end{array}$ & Clonidine \\
\hline
\end{tabular}


unaware of their condition. In fourteen patients, blood pressure levels were so high, reaching JNC VI stage III classification, that patients had to be sent immediately for medical attention. The dental school recognized and referred almost half of the hypertensive patients for diagnosis and treatment.

Until recently, studies examining the prevalence of hypertension within a dental school patient population were very limited. However, in 2001, at the University of Mississippi School of Dentistry a similar study was undertaken in an attempt to identify the relative size of the hypertensive population treated at the dental school. Patient records were reviewed over a four-year span. Criteria included diagnosis of hypertension by a physician or presentation with a systolic reading of greater than $140 \mathrm{~mm}$ $\mathrm{Hg}$ and/or a diastolic reading of greater than $90 \mathrm{~mm}$ $\mathrm{Hg}$. The prevalence of diagnosed hypertension in the study population was 16.6 percent. When the population exhibiting elevated blood pressure without a previous diagnosis was included, the prevalence of hypertension rose to 27.9 percent. $^{7}$ Thus, in similar examinations of hypertension in patient populations, both studies found that greater than 25 percent of patients treated at a U.S. dental school were hypertensive.

Based on the JNC VI report, the American Dental Association supports that blood pressure readings should be taken at every dental appointment; thus, the ADA position stands as a rule of thumb for practicing dentists. However, recommendations are not definitively stated as guidelines, so consequently they are not routinely followed in a dental practice and the quality of hypertension care remains suboptimal. $^{3}$

The prevalence of hypertensive patients seen at the dental school is also overlooked. The number of charts that did not meet the study criteria indicates that student dentists at time neglected to take patients' blood pressure. Nine hundred seventy-six patient charts were examined in order to obtain 500 that met the designated criteria. Thus, 476 charts failed to meet the criteria. Many of those 476 charts had to be discarded from the study because they did not contain any notation about blood pressure reading in the designated clinical examination form. Even more disconcertingly, students did not correlate patients' medical health histories to rule out the possibility of hypertension, and sometimes high blood pressures (JNC II, JNC III) were ignored. Blood pressure readings were not taken for sixteen patients who had medical history forms indicating that they had a history of hypertension.

Hypertensive patients' health is jeopardized each time they are treated without thorough examination of their backgrounds, medical histories, medical treatments, and current blood pressures. Furthermore, if routine blood pressures are not taken, opportunities to screen for hypertension are lost. Dental care in hypertensive patients can be complicated, since any procedure causing stress is likely to increase an already elevated blood pressure and can result in acute complications such as a cardiac arrest or a cerebrovascular accident, retinal insufficiency, or combination of these. ${ }^{6}$ Chronic complications of hypertension, especially impaired renal function, can affect dental management. With such a high occurrence of hypertensive patients receiving treatment, it is of utmost importance to screen for hypertension at initial appointments and monitor at subsequent visits.

With the exception of a slight drop in the total percentages of hypertensive patients in their forties and seventies, the general prevalence of hypertension increased incrementally with age. In this study's population, the age group of fourteen to nineteen years had a 13 percent prevalence of hypertension; those twenty to twenty-nine years had a 17.2 percent prevalence rate; those thirty to thirty-nine years had a 32.4 percent prevalence rate; those forty to forty-nine years had a 25.3 percent prevalence rate; those fifty to fifty-nine years had a 64.2 percent prevalence rate; those sixty to sixty-nine years had a 75 percent prevalence rate; those seventy to seventynine years had a 58.8 percent prevalence rate; and those eighty to eighty-nine years had a 100 percent prevalence rate. The age group of ninety to ninetynine years presented a 40 percent prevalence rate; however, only five persons were in this age group (see Table 3). The demonstration of this population's general rise in hypertension with increasing age is consistent with the national trend as reported by both the American Heart Association and the American Society of Hypertension. ${ }^{4}$

There is also a gender difference regarding the prevalence of hypertension. In younger people, hypertension is more common among men than women. With increasing age, however, more women than men are afflicted with it. These trends correlate with the examined hypertensive population as seen in Figure 5. In this study, the prevalence of hypertension in males is more frequent in their twenties and thirties, 


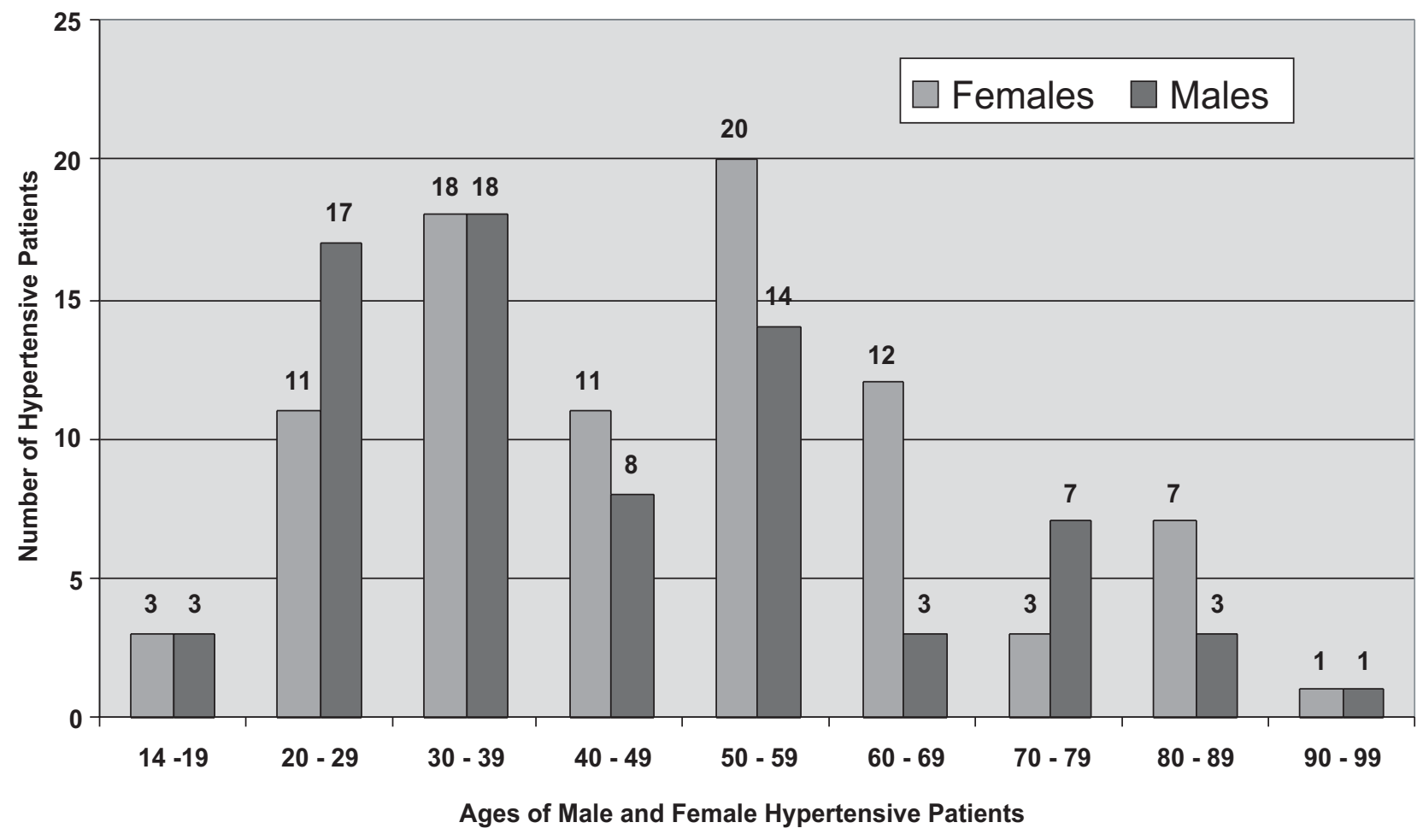

Figure 5. Gender breakdown within different age groups in the hypertensive population

and the occurrence of hypertension in females steadily increased with age, surpassing males after age forty (the only exception being a sharp increase in hypertension found in males in their seventies).

It is important for dentists to be aware of the medications his or her patients are taking. Dentists need to inform patients that hypertension may have serious health consequences and could necessitate changes in their dental treatment. Dental care should focus on the actions, interactions, and adverse effects of antihypertensive medications as well as the prevention of hypertensive crisis. Practitioners should measure blood pressure at every visit and inform the patient's primary health care provider of large variations from normal blood pressure ranges. ${ }^{9}$ In addition, antihypertensive medications have many dental considerations that dentists must be aware of before treating patients. Patients taking diuretics and agents that are anticholinergic or have anticholinergic effects are at increased risk of developing root caries due to decreased salivation, a potential side effect of these medications. ${ }^{9}$ Different antihypertensive medications can have adverse effects on the body with the concurrent use of local anesthetic with epi- nephrine or vasoconstrictors. Dentists should avoid using anesthetic solutions with vasoconstrictors in patients with uncontrolled hypertension, and elective dental procedures are contraindicated. ${ }^{9}$ Vasopressors and nonselective beta-blocker interactions have also been reported to precipitate a hypertensive episode. Whenever possible, dental practitioners should avoid administering local anesthetics with vasopressors in patients using nonselective betablockers. ${ }^{9}$

Dentists should further be aware of the importance of anxiety control of their (medicated and nonmedicated) hypertensive patients. Anxiety and psychosocial stressors have been linked to elevated blood pressure in susceptible patients. Practitioners may find it beneficial to premedicate with an anxiolytic agent the evening before the morning of a dental appointment when treating the anxious, hypertensive population. Nitrous oxide and afternoon appointments are also popular options for these patients. Dentists need to be aware of the orthostatic hypotensive-causing effects of antihypertensive medications affecting the sympathetic output or peripheral vasodilatory actions, such as -2-adrenergic 
agonists and -1-adrenergic antagonists. ${ }^{9}$ Patients using these types of antihypertensive medications should avoid rapid postural changes. Dental professionals should have little difficulty in treating patients with well-controlled hypertension and rarely have to make adjustments from normal patient care protocols. ${ }^{9}$ Table 4 displays the types and frequencies of medications taken by hypertensive patients in the examined patient population.

Tobacco was also recorded for both normotensive and hypertensive patients in this study. Though not significant, the incidence of tobacco use was higher in hypertensive patients than normotensive patients ( 58.1 percent versus 56.6 percent). Tobacco use is a major contributor to hypertension and can increase the severity of hypertension. ${ }^{3}$

It should be noted that the data was collected at random from an allotted one-year span of time and the data was of a limited sample size and taken from patients' charts who reside primarily in Ann Arbor, Michigan, and surrounding midwestern areas. Although efforts were made to demonstrate that findings of the study were representative of national findings, assessments may not necessarily apply to the other demographic areas of the United States.

Based on the evidence presented in this study, dentists should place an emphasis on the detection and referral of patients suffering from high blood pressure. ${ }^{5}$ It is important that blood pressure readings be taken before each initial and recall dental appointments. Patients with hypertension, cardiovascular disease, and endocrine disease will need their blood pressures taken at each dental appointment. Guidelines for U.S. dental schools and practitioners should be established in accordance with the findings of the Joint National Committee on Detection, Evaluation, and Treatment of High Blood Pressure. ${ }^{2}$ The goal of this study was to create an awareness of the current problems in the diagnosis and treatment of hypertensive patients in the dental community, so that steps can be taken towards improving current conditions.

\section{Acknowledgments}

We would like to thank the central records department at the University of Michigan School of Dentistry for assistance in locating the 1,000 records used in this study. We would also like to acknowledge Dr. Diane Kiino, Ph.D., of Kalamazoo College for her assistance in the research manuscript.

\section{REFERENCES}

1. Chobanian AV, Bakris GL, Black HR, Cushman WC, Green LA, Izzo JL, Jr., et al. The seventh report of the Joint National Committee on Prevention, Detection, Evaluation, and Treatment of High Blood Pressure: the JNC 7 report. JAMA 2003;289(19):2560-72.

2. National High Blood Pressure Education Program. The sixth report of the Joint National Committee on Detection, Evaluation, and Treatment of High Blood Pressure. Arch Intern Med 1997;157:2413-46.

3. Trilling JS, Froom J. The urgent need to improve hypertension care. Arch Fam Med 2000;9:794-801.

4. Patient information guide to understanding hypertension. New York: American Society of Hypertension, 1999-2000.

5. Fahey TP, Peters TJ. What constitutes controlled hypertension? patient based comparison of hypertension guidelines. Br Med J 1996;313:93-6.

6. Glick M. New guidelines for prevention, detection, evaluation and treatment of high blood pressure. J Am Dent Assoc 1998;129(11):1588-94.

7. Gordy FM, Le Jeune RC, Copeland LB. The prevalence of hypertension in a dental school patient population. Quintessence Int 2001;32(9):691-5.

8. Little JW. The impact on dentistry of recent advances in the management of hypertension. Oral Surg Oral Med Oral Pathol Oral Radiol Endod 2000;90:591-9.

9. Muzyka BC, Glick M. The hypertensive dental patient. J Am Dent Assoc 1997;128(8):1109-20. 